\title{
The spread of the Argentine ant: environmental determinants and impacts on native ant communities
}

\author{
Núria Roura-Pascual · Josep M. Bas • \\ Cang Hui
}

Received: 24 April 2009/Accepted: 10 November 2009/Published online: 21 November 2009

(C) Springer Science+Business Media B.V. 2009

\begin{abstract}
The increasing numbers of invasive species have stimulated the study of the underlying causes promoting the establishment and spread of exotic species. We tracked the spread of the highly invasive Argentine ant (Linepithema humile) along an environmental and habitat gradient on the northeastern Iberian Peninsula to determine the role of climatic, habitat and biotic variables on the rate of spread, and examine impact on native ant communities. We found the species well-established within natural environments. The mean annual rate of spread of the invasion $(7.94 \pm 2.99 \mathrm{~m} /$ year $)$ was relatively low compared to other studies, suggesting that resistance posed by native ants in natural environments with no or low human disturbance might delay
\end{abstract}

Electronic supplementary material The online version of this article (doi:10.1007/s10530-009-9650-x) contains supplementary material, which is available to authorized users.

N. Roura-Pascual · J. M. Bas

Departament de Ciències Ambientals, Universitat de Girona, Campus de Montilivi, 17071 Girona, Catalonia

N. Roura-Pascual · C. Hui

Centre for Invasion Biology, Department of Botany and Zoology, University of Stellenbosch, Private Bag X1, Matieland 7600, South Africa

N. Roura-Pascual ( $\square)$

Àrea de Biodiversitat, Centre Tecnològic i Forestal de Catalunya, Ctra. de St. Llorenç de Morunys km 2,

25280 Solsona, Catalonia

e-mail: nrourapascual@gmail.com (although not prevent) the spread of the invasion irrespectively of the land-use type. Factors related to the distance to urban areas and characteristics of native and introduced populations explained the rate of spread of the invasion, while habitat-related variables determined the distribution of native ants and the impact of the Argentine ant on them. Native ant communities became more homogeneous following the invasion due to the decline of species richness and abundance. Only few species (Plagiolepis pygmaea and Temnothorax spp.) were able to cope with the spread of the invasion, and were possibly favored by the local extinction of other ant species. Taken together, our results indicate that land uses per se do not directly affect the spread of $L$. humile, but influence its invasive success by molding the configuration of native ant communities and the abiotic suitability of the site.

Keywords Biological invasions - Biotic homogenization · Functional groups ·

Mediterranean-type ecosystems .

Occupancy-abundance relationships

\section{Introduction}

The mechanisms and processes facilitating the movement of exotic species have received considerable attention in the literature (Wilson et al. 2009), partly because of the increasing number and impact of 
introduced species globally. Long-distance dispersal mediated by humans is thought to be responsible for the introduction of species into new biogeographic regions, which were previously inaccessible through natural dispersal (Mack and Lonsdale 2001). The successful establishment and spread of these exotic species depends, however, on both the characteristics of the species (invasiveness) and recipient environment (invasibility; Richardson and Pysek 2006). Introduced species have to tolerate the abiotic conditions of the new environment and overcome the resistance posed by native biota. These species will be considered invasive once they have been able to establish, reproduce and spread without human assistance. It is at this stage that exotic species become a major cause of concern for the hosting ecosystem and native communities (Richardson et al. 2000).

The influence of the abiotic environment together with biotic interactions in determining the spread of biological invasions has been studied at various spatial scales (Pauchard and Shea 2006). At global scales, climatic conditions appear to regulate the distribution of species, whereas biotic interactions have a wider influence at local scales (Willis and Whittaker 2002). Habitat-related variables have been observed to regulate the occurrence and abundance of species at local scales (Andren 1994), but few studies have assessed the role of habitats in relation to climatic conditions, interactions with native species and characteristics of introduced populations in determining the spread of invasive species.

Here we examine the influence of abiotic and biotic suitability in favoring the spread of invasive species at local scales, by using the Argentine ant (Linepithema humile Mayr) as a case study. Several studies have investigated the influence of climatic conditions and native ant communities on the spread by diffusion of the Argentine ant (Carpintero and Reyes-Lopez 2008; Holway 1998; Human and Gordon 1996), but few have explored the influence of these factors together across a habitat gradient (Cammell et al. 1996; Way et al. 1997). Previous investigations suggest that incipient propagules of Argentine ants establish initially at the edge of urban areas, and these human-modified environments promote the growth and establishment of initial populations (Bolger 2007; Suarez et al. 1998). The species then spreads through riparian corridors that have the appropriate levels of humidity for their survival (Menke et al. 2007; Schilman et al. 2007). Consequently, even though the capacity of the species to occupy a wide range of natural habitats has been reported (Suarez et al. 2001), most investigations have been conducted close to urban areas or in low scrub vegetation types (de Kock and Giliomee 1989; Human et al. 1998; Menke et al. 2007).

The aim of this study was to disentangle the roles of abiotic factors such as habitat and climate, and biotic factors related to the characteristics of native ant species and introduced populations in shaping the spread by diffusion of this highly invasive species at local scales. We examine changes in the abundanceoccupancy relationship between native and invaded ant communities across land uses, and study the spread of $L$. humile along an environmental gradient. By doing so, we address the following questions: (1) which factors determine the rate of spread of the Argentine ant invasion; and (2) how do native ant communities respond to Argentine ant invasion. These answers contribute significantly to our understanding of the susceptibility of native communities and habitats to the invasion, as well as providing a new perspective to contextualize previous studies on the spread of the Argentine ant. Furthermore, our analyses also set up an integrated framework to understand the role of abiotic and biotic factors, and particularly habitat-related variables, in driving invasion at local scales.

\section{Methods}

Sampling method

We followed the spread of the Argentine ant along a North-South environmental gradient in the Costa Brava (NE Iberian Peninsula, Fig. 1). The analysis was conducted in the major land-use types, including dry cultivated fields $(L D U-d f)$, shrublands (dominated by Quercus coccifera; $L D U-s h$ ), poplar plantations (Populus nigra; LDU-pp), pine forests (Pinus halepensis; $L D U$-pf), and cork oak forests (Quercus suber; $L D U$ - $c f$ ). For each land use, we selected three to five sites that were already undergoing active invasive spreading and set up transects (separated by $20 \mathrm{~m}$ ) perpendicular to the front. The number of transects per site (between three and eight) and their length 


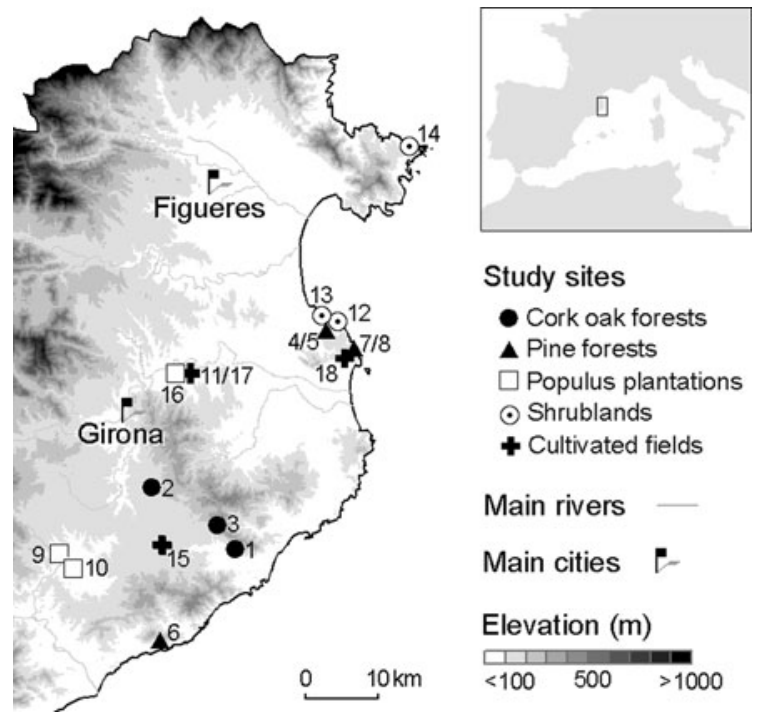

Fig. 1 Location of the Costa Brava in relation to the Iberian Peninsula (SW Europe), and of the 18 study sites used to measure the rate of spread of the Argentine ant. Different site symbols correspond to different land uses. See Table S2 for the names of the different sites, and the number of transects set in place

$(124.5 \pm 37.8 \mathrm{~m}$; mean $\pm \mathrm{SE})$ varied depending on the extent and topographic constraints of the sites. Marmalade baits were placed along transects at intervals of $3.5 \mathrm{~m}$, which were visited two hours later for recording the identity and abundance of ants species at the bait level (abundance scale from 1 to 5 , with 0 indicating absence; $1=1-5$ workers, $2=6-$ 25 workers, $3=25-100$ workers, $4=100-1,000$ workers, $5 \geq 1,000$ workers).

We surveyed a total of 85 transects from 18 sites, but only included 54 transects from 14 sites in the analysis (Fig. 1). Some transects were excluded because they were completely invaded (i.e. site 10) or the disturbance regime limited the distribution of ant species (i.e. dry cultivated fields from sites 15, 16 and 17 were ploughed intensely, and ants were limited to the edge of the fields). The analyses related to dry cultivated fields were only based on eight transects from one site (i.e. site 18), where human disturbance was low enough to allow ant communities to establish. As a result, the final 54 transects represented a gradient of natural habitats with various degrees of human disturbance.

Even though ground bait transects present some limitations in characterizing the diversity and abundance of ant communities in comparison with other methods (e.g. pitfall traps), their easy installation and monitoring allowed us to sample a wide range of environmental conditions and characterize introduced populations (Alder and Silverman 2004; Casellas et al. 2009). We identified the limit of the invasion front in 2005 by using the first bait occupied by Argentine ants, and measured the annual spread by diffusion of the invasion by repeating the procedure in 2006. In case the Argentine ant occupied the whole transect in 2006, extra baits were added along the invading direction until no Argentine ants were recorded. Because this 1-year field sampling might mask fluctuations in the spread of the invasion due to changes in environmental conditions and seasonal population dynamics (Heller and Gordon 2006), fluctuations were minimized by restricting the sampling to the highest period of activity of the Argentine ant (i.e. June to August, from 6 to $11 \mathrm{~h}$ or from 16 to $22 \mathrm{~h}$; Abril et al. 2007). There were no significant differences in the mean temperature and precipitation between the 2005 and 2006 sampling periods for any of the 20 weather stations located in the Costa Brava (being $P=0.067$ for the lowest value of all KruskalWallis Tests; SMC 2006), and thus we assumed that the Argentine ant and native communities had the same seasonal momentum in both years.

Because transects did not always have the same number of baits in both uninvaded and invaded areas, for the analyses we limited the number of baits in each area to the minimum number of baits present in any of the two areas. For example, if one transect had 20 baits in the uninvaded area and 25 baits in the invaded area, we excluded the five invaded area baits which were most distant from the invasion front. The final number of utilized baits in uninvaded and invaded areas was 1,329 each, with 191 baits in cork oak forests, 577 in pine forests, 147 in poplar plantations, 261 in shrublands and 153 in dry cultivated fields. This manipulation was necessary to derive reliable estimates of the influence of factors determining the spread of the invasion and also assess changes in native ant communities, as described in the next sections.

Factors determining the rate of spread of the Argentine ant invasion

We related the annual rate of spread by diffusion (ARS; measured in m/year) of the Argentine ant at the 
transect level to different biotic and abiotic variables to identify the most influential factors (Table S1). In addition to land uses $(L D U)$, we included two habitatrelated variables in the analysis: distance to urban areas $(D T U ; \mathrm{m})$ and distance to the sea $(D T S ; \mathrm{m})$ that are known to influence the spread of the species (Carpintero et al. 2004; Espadaler and Gómez 2003). Data from climatic atlases were also used to characterize the study sites according to: minimum winter temperature $\left(M W T\right.$; tenth of $\left.{ }^{\circ} \mathrm{C}\right)$, annual precipitation $(A P R$; tenth of $\mathrm{mm})$ and annual solar radiation $(A S R$; $10 \mathrm{~kJ} / \mathrm{m}^{2} \times$ day; Ninyerola et al. 2000). $M W T$ was obtained by calculating the mean minimum temperatures of winter months (December to March), when the species has the lowest foraging activity and aggregates to form winter colonies (Abril et al. 2007; Carpintero et al. 2007; Heller and Gordon 2006). Because distance to the sea and climatic variables were highly correlated $(r>0.5)$, we conducted a principal components analysis to summarize the variation of the original variables and used the first component (abbreviated as CLI) as surrogate of climatic variables using STATISTICA 6.1 (StatSoft Inc.). This first component explained $78 \%$ of the variation, and described a gradient going from wet and temperate areas to dry and cold areas (Spearman's correlations of 0.921 for DTS, -0.962 for $M W T, 0.917$ for APP, and 0.717 for ASR). These habitat and climate-related variables were calculated at the site level due to the characteristics of the sampling design and the resolution of digital climatic layers.

The variables describing the introduced populations and native communities were, on the contrary, measured at the transect level. For variables based on abundance information, the categories recorded during the field work were converted to number of workers considering: $0=0$ workers, $1=1$ workers, $2=10$ workers, $3=100$ workers, and $4-5=1,000$ workers. The two variables chosen to represent the characteristics of introduced populations were: the mean density of workers in the invaded area in 2005 $(D E N)$ and the difference in the aggregation of Argentine ants (DIA). Density of individuals has been widely applied as an indicator of the propagule pressure (Lockwood et al. 2005), and it was calculated as the mean number of workers (log-transformed to improve normality) present in the invaded area of each transect. Difference in aggregation has otherwise rarely been used in biological invasions. Wilson et al. (2004) showed that species aggregation patterns are sensitive predictors of species range expansions and retractions, with expanding species showing stronger aggregated structure (Johnson 1998). Here, we measured the aggregation using the Morisita Index (Hurlbert 1990),

$I_{\mathrm{M}}=\frac{n}{n-1}\left(\frac{1}{\mu}\right)\left(\frac{\sigma^{2}}{\mu}+\mu-1\right)$

where $n$ is the number of samples (baits in invaded area), $\mu$ and $\sigma^{2}$ the mean and the variance of the number of workers in the baits present in the invaded area of each transect. $I_{\mathrm{M}}$ measures the relative likelihood of two randomly selected individuals being from the same sample (bait) compared with the situation that the population is randomly distributed. Thus, a high $I_{M}$ indicates a high variance of the number of workers in the baits, and suggests that individuals tend to cluster together in space. The Morisita Index is closely related to Lloyd's crowding index $\left(I_{\mathrm{L}}=(n-1) /\left(n \times I_{\mathrm{M}}\right)\right)$, and is a robust spatially implicit measurement of the arrangement of the individuals composing a population (Hurlbert 1990). Difference in aggregation was therefore measured as the difference in the Morisita Index between 2006 and 2005 for Argentine ants in the invaded area of each transect $\left(D I A=I_{\mathrm{M}(2006)}-I_{\mathrm{M}(2005)}\right)$, and this difference is expected to be higher in transects showing a fast rate of spread than in transects where the advance of the invasion is slow.

To explore the influence of biotic interactions with native ants, we also included five measurements related to the assemblage of native ant communities. We first selected the mean density of all workers (log-transformed) in the uninvaded area of each transect $(M D N)$ as a general descriptor of the abundance of the native ants. Second, ant diversity was measured using the Simpson Evenness Index (Magurran 1988),

$\mathrm{SEI}=\frac{1}{S \times \sum p_{i}^{2}}$

where $S$ is the species richness and $p_{i}$ the proportion of workers from each species $i$ relative to the total number of workers present in the uninvaded area of each transect. SEI includes information on species richness and relative abundance of each species and ranges between 0 and 1 , with 1 indicating complete 
evenness of species abundance. Another important measure of ants' assemblage is the species turnover (i.e. beta diversity, see Gotelli and McCabe 2002; Hui and McGeoch 2008). We used the Jaccard index $\left(\beta_{J}=\right.$ number of shared species/total number of species) to measure the spatial and temporal turnover rate of native species (Koleff et al. 2003; Lennon et al. 2001). The spatial turnover (STO) refers to the species turnover between uninvaded and invaded areas in each transect in 2005, and the temporal turnover (TTO) refers to the species turnover between uninvaded areas in each transect in 2005 and 2006.

A linear mixed model was used to analyze the relationship between the annual rate of spread (ARS) and the 9 biotic and abiotic variables (Table S1) at the transect level, considering sites (14 levels) as random factors. Since the distribution of the response variable $(A R S)$ is not significantly different from normal (Shapiro-Wilk Test, $P=0.29$ ), we used a normal distribution to model the error structure of the data and assumed an identity link function. The parameters of the model were fitted by maximum likelihood, implemented within the nlme package (Pinheiro et al. 2008) for R (R Development Core Team 2008). We used the best-subsets approach to model building, examining all 511 possible models and chose the simplest plausible model with the fewest possible number of variables based on Akaike Information Criterion for small samples (AICcl; Burnham and Anderson 2004; Quinn and Keough 2002). A likelihood ratio test was then used to confirm that the model selected using AICc explained a significantly greater amount of variance than simpler models based on log-likelihood ratio statistics and the number of parameters in each model. If the $P$ value did not drop significantly $(>0.05)$ by decreasing one variable, then we chose the model with fewer variables (Lindsey 2000).

Response of native ant communities to Argentine ant invasion

To investigate the response of native ant communities to the spread of the Argentine ant invasion, we calculated the species occupancy and abundance at the site level. Due to differences in the sampling effort among sites, we could not investigate differences in ant assemblage among sites at the transect level. All transects within a site were pooled together.
Species occupancy was calculated from the number of baits occupied in each site, and species abundance by summing the total number of workers after converting the abundance categories to number of workers as done in the previous analysis. We compared the occupancy-abundance relationship (log-transformed) of ant species between uninvaded and invaded areas across functional groups and landuse types (Blackburn et al. 2006; Gaston and Blackburn 2000).

Ant species were assigned to seven functional groups according to their responses to the environmental stress and disturbance (Brown 2000). The functional groups considered were: Dominant Dolichoderinae $(D D)$, composed of abundant, highly competitive dominant ants; Suboridinate Camponotini $(S C)$, with frequently nocturnal foragers and behaviorally submissive to $D D$; Hot-climate Specialist $(H C)$ and Cold-climate Specialist $(C C)$, which reside only in arid and cold temperate regions respectively; Cryptic Species $(\mathrm{Cr})$, composed of small ants that forage in soil and leaf litter with few interactions with other ants; Opportunist $(O p)$, composed of weedy species that inhabit areas with high disturbances and compete poorly with other ants; and Generalized Myrmiciane (GM), which have generalized food resources and nesting requirements (Andersen 1995). Formica species were assigned to Opportunist instead of Cold-climate Specialists, and Tapinoma nigerrimum and L. humile were assigned to Dominant Dolichoderinae because of their behavioral dominance in Mediterranean habitats (Cerda et al. 1997). The assignation of these functional groups has proved successful in comparing the responses of ant communities to different land uses in the same study region (Gómez et al. 2003).

Furthermore, we examined changes in species occupancy between uninvaded and invaded areas at both land-use and species levels by means of a multidimensional scaling ordination technique. We measured the Euclidian distances among land uses using species as point data, and vice versa, to generate similarity matrices. These were used by the Guttman-Lingoes non-metric multidimensional scaling algorithm implemented in STATISTICA 6.1 (StatSoft Inc.) to locate each item in the lowest dimensional space that minimized the fit measure called Stress (Schiffman et al. 1981). Finally, we calculated the beta diversity index to estimate the 
turnover rate in species composition. The beta diversity index $\beta_{\text {sim }}\left(1 \geq \beta_{\text {sim }} \geq 0\right)$ is the proportion of unique species found in each land-use type after the invasion, with high values indicating high turnover rates (Koleff et al. 2003).

\section{Results}

Factors determining the rate of spread of the Argentine ant invasion

The mean annual rate of spread of the Argentine ant across land uses was $7.94 \pm 2.99 \mathrm{~m}$ /year (mean \pm $\mathrm{SE})$. The maximum rate occurred in dry cultivated fields $(15.75 \pm 6.56 \mathrm{~m})$, followed by cork oak forests $(13.31 \pm 4.91 \mathrm{~m})$ and pine forests $(12.47 \pm 5.13 \mathrm{~m})$. The spread in poplar plantations $(1.26 \pm 6.64 \mathrm{~m})$ was very slow and a slight range retraction was seen in shrublands $(-0.31 \pm 7.59 \mathrm{~m}$; Table S2). Despite these differences, the rate of spread of the Argentine ant did not differ (ANOVA: $F_{4,51}=1.18, P=0.33$ ) among land uses (Fig. S1).

The linear mixed model explaining the rate of spread of the Argentine ant selected by the bestsubset approach had three variables (model with the lowest AICc in Table 1), which included one habitat variable (distance to urban areas), one variable related to the structure of ant communities (temporal turnover in the uninvaded area) and one variable related to the characteristics of introduced populations (difference in aggregation). However, the likelihood ratio test indicated that the most parsimonious model was a 2-variable model consisting of one habitat variable (distance to urban areas) and one variable related to the characteristics of introduced populations (difference in aggregation). The likelihood ratio test of the best 1-variable model dropped significantly, and thus the 2-variable model was considered the best model (Table 1). Interestingly, the best 1-variable model included a variable related to the characteristics of introduced populations (difference in aggregation) and excluded the habitat variable distance to urban areas. Difference in aggregation was consistently included in all models (Table 1).

When the relation between the annual rate of spread and each explanatory variable was analyzed using a full linear mixed model (i.e. the 9-variable model), the relationship was significant for only one of the independent variables: difference in aggregation of introduced populations (Table 2). This variable was also considered significant in the univariate analysis (i.e. the 1-variable models), together with temporal turnover of native communities. Considering these two significant variables and distance to urban areas, we find that difference in aggregation of invaded populations and distance to urban areas present a positive effect on the response variable and the variable refereeing to native ant communities a negative effect.

Table 1 Minimum adequate linear mixed models explaining the rate of spread of the Argentine ant

\begin{tabular}{|c|c|c|c|c|c|}
\hline Model & $\mathrm{d} f$ & $\mathrm{AICc}$ & $\Delta \mathrm{AICc}$ & $\operatorname{logLik}$ ratio & $P$ \\
\hline$L D U+D T U+C L I+\log (D E N)+D I A+\log (M D N)+S E I+S T O+T T O$ & 15 & 526.924 & 23.097 & 5.188 & 0.818 \\
\hline$D T U+C L I+\log (D E N)+D I A+\log (M D N)+S E I+S T O+T T O$ & 11 & 515.756 & 11.929 & 2.357 & 0.798 \\
\hline$D T U+C L I+D I A+\log (M D N)+S E I+S T O+T T O$ & 10 & 512.659 & 8.832 & 2.342 & 0.673 \\
\hline$D T U+C L I+D I A+S E I+S T O+T T O$ & 9 & 509.780 & 5.953 & 2.246 & 0.523 \\
\hline$D T U+C L I+D I A+S T O+T T O$ & 8 & 506.975 & 3.148 & 2.201 & 0.333 \\
\hline$D T U+D I A+S T O+T T O$ & 7 & 505.040 & 1.213 & 1.406 & 0.235 \\
\hline$D T U+D I A+T T O$ & 6 & 503.827 & - & - & - \\
\hline$D T U+D I A$ & 5 & 504.124 & 0.297 & 2.811 & 0.094 \\
\hline$D I A$ & 4 & 506.079 & 2.252 & 7.182 & 0.028 \\
\hline
\end{tabular}

Models were selected using the Akaike Information Criterion for small samples (AICc) and a likelihood ratio test based on the loglikelihood ratio and the number of parameters included in the model (if the $P$ value did not drop significantly by decreasing one variable, we selected the model with fewer variables). Refer to the "Methods" or Table S1 for the abbreviations of the variables, but note that $C L I$ refers to the first component of the principal component analysis conducted using all climatic variables (DTS, MWT, $A P P$, and $A S R)$ and $\log$ indicates variables transformed logarithmically. The best-subset models are shown in bold 
Table 2 Statistics derived from the linear mixed model calibrated including all variables together (9-variables model) and each variable separately (1-variable models) to explain the rate of spread of the Argentine ant

\begin{tabular}{|c|c|c|c|c|c|c|}
\hline \multirow[t]{2}{*}{ Variables } & \multicolumn{3}{|l|}{ 9-variables model } & \multicolumn{3}{|l|}{ 1-variable model } \\
\hline & Estimate \pm SE & $F$-test & $P$ & Estimate \pm SE & $F$-test & $P$ \\
\hline$L D U$ & & 1.331 & 0.330 & & 0.808 & 0.550 \\
\hline$p f$ & $12.490 \pm 22.863$ & & & $-0.755 \pm 10.401$ & & \\
\hline$p p$ & $-5.889 \pm 21.731$ & & & $-10.471 \pm 12.303$ & & \\
\hline$s h$ & $8.189 \pm 34.423$ & & & $-13.696 \pm 11.166$ & & \\
\hline$d f$ & $18.205 \pm 24.531$ & & & $2.676 \pm 14.125$ & & \\
\hline$D T U$ & $0.053 \pm 0.091$ & 0.188 & 0.667 & $0.059 \pm 0.038$ & 2.342 & 0.134 \\
\hline$C L I$ & $7.188 \pm 9.058$ & 0.649 & 0.426 & $1.804 \pm 3.851$ & 0.219 & 0.642 \\
\hline $\log (D E N)$ & $-1.029 \pm 4.667$ & 0.391 & 0.536 & $-0.057 \pm 3.589$ & 0.000 & 0.987 \\
\hline$D I A$ & $1.083 \pm 0.480$ & 9.164 & 0.005 & $1.144 \pm 0.433$ & 6.974 & 0.012 \\
\hline $\log (M D N)$ & $-1.243 \pm 6.740$ & 0.084 & 0.774 & $1.039 \pm 4.808$ & 0.047 & 0.830 \\
\hline SEI & $-6.569 \pm 16.268$ & 0.674 & 0.417 & $-13.181 \pm 12.970$ & 1.033 & 0.315 \\
\hline STO & $-18.771 \pm 15.696$ & 0.940 & 0.339 & $-13.392 \pm 14.473$ & 0.856 & 0.360 \\
\hline TTO & $-24.225 \pm 15.257$ & 2.521 & 0.122 & $-31.286 \pm 12.316$ & 6.453 & 0.015 \\
\hline
\end{tabular}

Refer to the Methods or Table S1 for the abbreviations of the variables, but note that $C L I$ refers to the first component of the principal component analysis conducted using all climatic variables (DTS, MWT, APP, and ASR) and log indicates variables transformed logarithmically. The estimate and standard error for the sublevels of the land uses $(L D U)$ categorical variable were not presented because the variable was non-significant

Response of native ant communities to Argentine ant invasion

We recorded 32 native ant species (Table S3). Crematogaster scutellaris and Pheidole pallidula were notably present in cork oak forests, but only P. pallidula dominated pine forests and shrublands. Tapinoma nigerrimum, Lasius spp., Formica spp. and Tetramorium spp. were common in disturbed habitats (i.e. dry cultivated fields and poplar plantations ploughed once a year). Plagiolepis pygmaea was consistently found across land-use types and occurred at high occupancy levels, except in poplar plantations where its occupancy was low. With the spread of the Argentine ant, most species experienced a general decrease in occupancy (Table S3). P. pallidula was the most affected one, followed by $C$. scutellaris in cork oak forests, Camponotus cruentatus in pine forests, Tetramorium caespitum in poplar plantations, and Formica gagates in dry cultivated fields. P. pygmaea and Temnothorax spp. were able to resist the invasion. The occupancy of L. humile increased considerable across land-use types, except in shrublands.

The two-dimensional scaling analysis at the ant species level accounted for a considerable reduction in stress (Stress $=0.018$ ). The first dimension separated species positively affected by the invasion from those species negatively affected, while the second dimension differentiated species inhabiting woodland habitats from those present in habitats with a high degree of human disturbance (Fig. 2a). Equivalent patterns were also identified by the multidimensional scaling at the land-use level (Stress $=0.048$ ). The first dimension separated uninvaded from invaded land uses, while the second dimension differentiated land uses according to their woody structure and degree of disturbance (Fig. 2b). It is important to note that invaded land uses clustered together in relation to this second dimension, while uninvaded land uses aligned along the gradient.

Despite the loss of species and altered occupancy relationships post-invasion, there were no significant differences between the slopes of abundance-occupancy relationships for uninvaded and invaded areas (Fig. 3). In terms of the functional groups (Fig. 3), Cryptic species and Subordinate Camponotini did not show differences in the occupancy-abundance relationship between uninvaded and invaded areas, while the rest of the functional groups did. The nonsignificant difference in Cryptic species was due to 

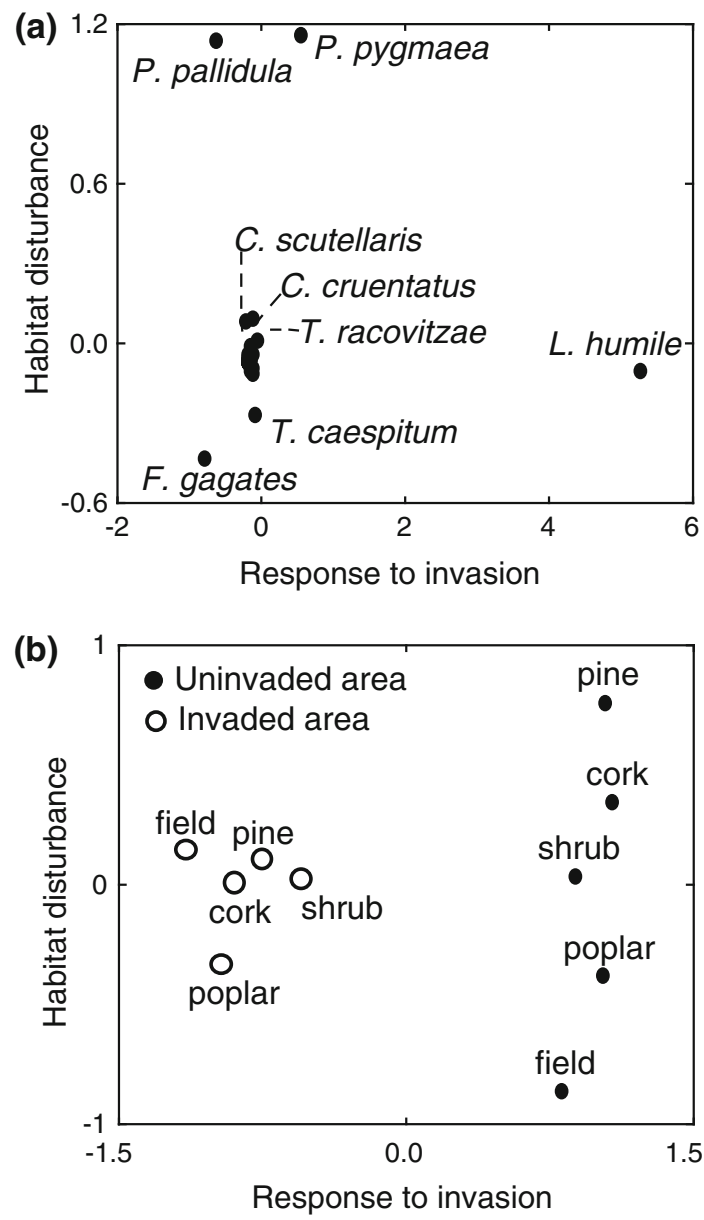

Fig. 2 Two-dimensional representations of the multidimensional scaling analyses conducted at (a) species and (b) land use levels, respectively. The land use abbreviations correspond to cork oak forests (cork), pine forests (pine), poplar plantations (poplar), shrublands (shrub), and dry cultivated fields (field)

the insensitivity of $P$. pygmaea to the invasion, which contrary to most ant species increased in abundance after the invasion. Opportunists, Cold-climate specialists and Generalized myrmicinae experienced a general decrease in both occupancy and abundance after the invasion, with the Generalized myrmicinae group showing the largest decline due to the sensitivity of $P$. pallidula to the invasion. Only Cold-climate specialists of the Temnothorax genus showed an increase of their occupancy-abundance ratio. It was not possible to examine occupancy-abundance relationships for Dominant Dolichoderinae and Hotclimate Specialists groups because of the reduced number of species included in the analysis (Table S3).
Fig. 3 Graphs showing the species' occupancy-abundance relationship (log-transformed) between uninvaded and invaded areas pooling all transects together (first row), and differentiating among functional groups (left column) and land uses (right column). Differences between the slopes of the abundance-occupancy relationship for uninvaded and invaded areas were measured using a $t$-test

With respect to land-use types, while the abundance-occupancy relationships in cork oak forests and dry cultivated fields were not significantly different, the relationship differed in the other land uses. Results from dry cultivated fields may have been influenced by the low number of species. These results were corroborated to some extent by changes in species turnover. Poplar plantations and shrublands were the most affected (beta diversity index, $\beta_{\text {sim }}=0.33$ and $\beta_{\text {sim }}=0.27$, respectively), whereas the ant assemblage in dry cultivated fields appeared to be more robust $\left(\beta_{\text {sim }}=0\right)$. Pine and cork oak forest presented intermediate values $\left(\beta_{\text {sim }}=0.14\right.$ and $\beta_{\text {sim }}=0.11$, respectively).

\section{Discussion}

Factors determining the rate of spread of the Argentine ant invasion

Contrary to observations of the spread of the Argentine ant that limit the invasion to riparian corridors or around human habitations (Carpintero et al. 2004; Menke et al. 2007; Ward 1987), we found the invasion well-established within natural habitats with different vegetation types and degree of human disturbance. Even though the starting point of the invasion could have been human-affected areas, observations during field sampling indicate that the species is able to spread across various land uses when the abiotic and biotic conditions are favorable (de Kock and Giliomee 1989; Krushelnycky et al. 2005; Roura-Pascual et al. 2009; Way et al. 1997).

We did not find a consistent pattern in the spread of the Argentine ant across land uses, but forests and dry cultivated fields with a low degree of human alteration clearly favored the spread of the invasion more than shrublands and poplar plantations (Fig. S1). However, results from dry cultivated fields are from a single site, which might not be representative given that three sites classified as dry cultivated fields 
Total occupancy-abundance relationship $t_{56}=1.09, P=0.28$
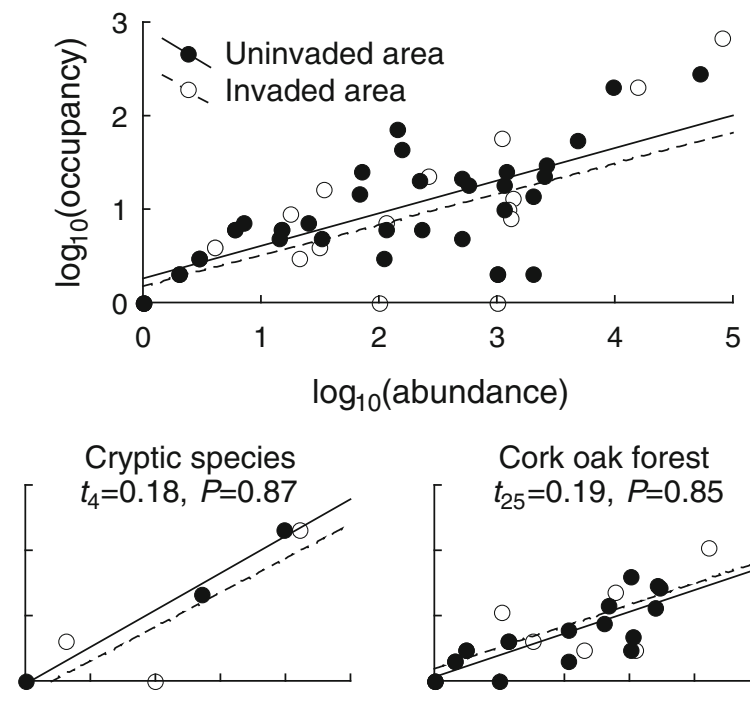

Subordinate Camponotini

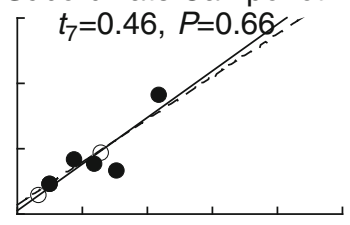

Opportunists

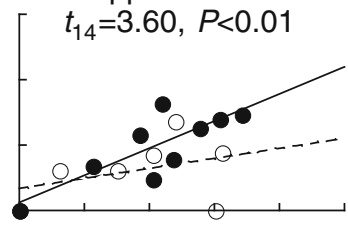

Cold-climate specialists

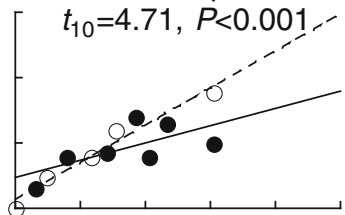

Generalized myrmicinae

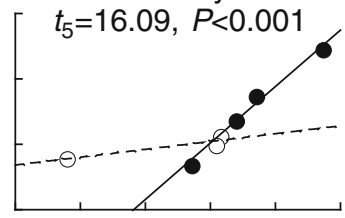

Cork oak forest

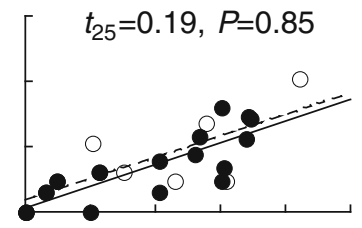

Pine forest

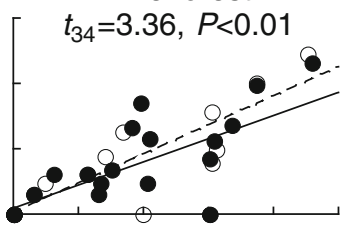

Poplar plantation

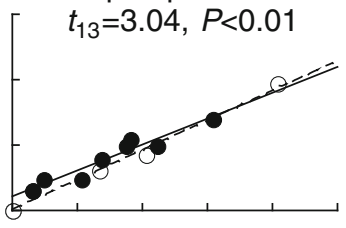

Shrubland

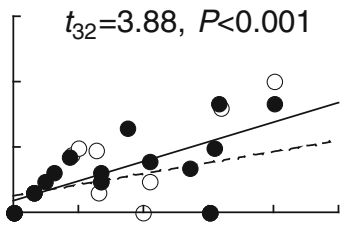

Dry cultivated field

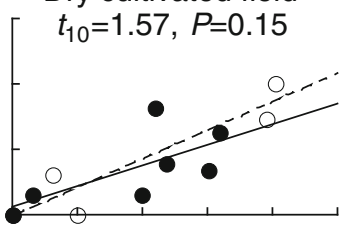

had to be excluded. The distribution of the Argentine ant in these three sites presenting a high degree of human disturbance was limited to the margins of the fields where human activities permitted the establishment of the colonies (Bolger 2007). Shrublands

included in our study were close to coastal areas, characterized by low levels of soil moisture and the presence of rocky soils, and poplar plantations subject to seasonal fluctuations as a consequence of human activities (i.e. field plough). Therefore, the high variability in the spread of the invasion in shrublands and poplar plantations could be explained by the enormous heterogeneity of these habitats at local scales (Retana and Cerda 2000). In contrast to Way et al. (1997), we found no differences in the spread of the Argentine ant between pine and cork oak forests; rates were similar to the $30 \mathrm{~m} /$ year recorded by these authors in oak forests in Portugal. However, they were much slower than the $150 \mathrm{~m} /$ year from various areas around the world (Suarez et al. 2001).

Nevertheless, we have to emphasize that the landuse type played a minor role in determining the annual rate of spread of the Argentine ant. Land uses $(L D U)$ was the first variable excluded from the bestsubset analysis (Table 1). In contrast, distance to urban areas and the characteristics of the introduced populations and native communities explained most of the variance. The relevance of distance to urban areas in all best-subset models explaining the spread of the invasion is similar to that found in previous studies (Carpintero et al. 2004; Espadaler and Gómez 2003). However, the positive effect of distance to inhabited areas in both full and univariate models suggests that sites close to populated places will present a lower rate of spread than more distant sites (Table 2). This is in contrast with the described pattern of the species worldwide, where high rates are expected to occur in areas with a high propagule pressure favored by human influence (e.g. areas close to initial sources of introduction, such as human habitations; Suarez et al. 1998). This counterintuitive result can be explained by the relative proximity of all sampled sites to urban areas (between 32 and $436 \mathrm{~m}$, Table S1). The Costa Brava is a highly humanized region, and the positive effect of distance to urban areas on the spread of the invasion can be related to the degree of establishment of the introduced populations. Populations close to urban areas could be at an initial stage of the invasion, and therefore spread at a lower rate than well-established populations of L. humile.

The inclusion of one variable characterizing native ant communities in one of the best-subset models 
(such as temporal turnover) and his negative effect on the full and univariate models suggest that interactions with native species could delay the spread of the invasion to some extent (Tables 1 and 2). The relatively low rates of spread of the Argentine ant found in our study compared to other studies (Suarez et al. 2001) could thus be partly attributable to the resistance posed by native ants. Fierce interspecific competition from ant communities in natural environments could delay (although not prevent) the spread of the invasion (Table 2), while highly disturbed habitats with a disrupted ant community (i.e. urban environments) would favor it (Carpintero et al. 2007; Way et al. 1997). However, the most relevant variable in determining the rate of spread is a measure related to the characteristics of the invasive populations: the difference in aggregation of Argentine ants between 2006 and 2005 in invaded areas (DIA). The inclusion of this variable (related to the size and structure of already established populations) in all best-subset models shows that the spread of the invasion occurs when established colonies reach a certain critical mass. The importance of the numeric superiority of workers to explain the spread of the Argentine ant has been highlighted by Holway (1999), who suggests that this numerical advantage is key to the success of the invasion. The most parsimonious model, however, indicates that difference in aggregation alone do not explain the rate of spread of the Argentine ant in the Costa Brava. Distance to urban areas is also important. Introduced populations close to populated places but at an initial stage of the invasion will present a lower rate of spread than more distant areas with more established populations, which have the appropriate critical mass to permit the advancement of the invasion front.

The reasons behind the exclusion of the other variables from the set of best models (Table 1) are both ecological and methodological. The exclusion of the climatic variable (i.e. first component of a principal component analysis on minimum winter temperatures, annual solar radiation, annual precipitation and distance to sea) from the best-subset models was unexpected considering previous studies (Krushelnycky et al. 2005; Menke et al. 2007; Schilman et al. 2007). Linepithema humile generally copes better with low temperatures than native ants (Abril et al. 2007; Jumbam et al. 2008), but the amount of heat (in degree days) required for an egg of Argentine ant to develop into an adult (Hartley and Lester 2003) and the low tolerance of adults to reduced levels of humidity (Schilman et al. 2007) restricts the expansion of the species to areas with high level of solar radiation and receiving a certain amount of rainfall (Heller et al. 2008). The exclusion of this variable from the best-subset models, however, could be attributable to the environmental suitability of the Costa Brava for the Argentine ant (Roura-Pascual et al. 2009). The study was conducted along a latitudinal gradient, where the relative proximity to the sea $(<21 \mathrm{~km}$, Table S1) could have smoothed the climatic variations among the different sampled sites.

On the other hand, the irrelevance of other variables characterizing native communities (mean density and Simpson evenness index, and spatial turnover to a less extent) in explaining the rate of spread of the species indicates the competitive superiority of $L$. humile to the native ants. However, the insignificant contribution of these variables, as well as the density of invasive workers per bait, in determining the annual spread rate could also be due to the nature of the sampling design. The use of bait transects restricts the detection of ant diversity towards diurnal species that are highly effective in monopolizing non-transportable resources, and therefore underestimates the presence and abundance of the non-diurnal species. The inherent limitation of using baits transects, however, is compensated by their easy installation that allows a fast examination of the invasion across a wide range of habitats (Alder and Silverman 2004). Overall, our results indicate that once established in a new area hosting appropriate conditions for its development thanks to human influences, the resistance posed by native ants is not an impediment for $L$. humile to spread and conquer new territories due to its numeric superiority.

Response of native ant communities to Argentine ant invasion

The distribution of ant communities found in our study coincide with previous studies conducted in the Iberian Peninsula (Cammell et al. 1996; Way et al. 1997), and corroborates the influence of habitatrelated factors (vegetation structure and the degree of disturbance) in molding the diversity of ant species in human-dominated landscapes (Gómez et al. 2003). Native ants segregated spatially according to their 
preference for woodlands (i.e. cork oak and pine forests, and shrublands) or disturbed habitats (poplar plantations and dry cultivated fields). At high levels of disturbance, however, their distribution was limited to the margins of the habitats where conditions were more favorable for the establishment of the colonies (Fig. 2).

With the spread of the Argentine ant, few species are able to resist the invasion. The most affected species seem to pertain to the Generalized myrmicinae and Opportunist functional groups. In contrast, Cryptic species and some Cold-climate specialists (principally species from the genus Temnothorax) do not decrease but increase their occupancy considerably after the invasion (Table S3). This is especially true for Temnothorax racovitzae across all land uses, and $P$. pygmaea in pine forests and dry cultivated fields. These species cope well with the invasion because of their reduced sizes and subordinate nature (i.e. species with a reduced foraging area, and exploiting a sub-optimal niche; Carpintero and Reyes-Lopez 2008; Passera 1994; Retana and Cerda 2000). In fact, Argentine ants might favor them by reducing their interspecific competition with other native ants. Overall, the impact of $L$. humile in native ant communities is high for dominant species with similar niche characteristics (such as $P$. pallidula and C. scutellaris) and also in more disturbed habitats with a less structured ant community dominated by opportunistic species (such as T. caespitum and F. gagates; Carpintero et al. 2007; Haskins and Haskins 1988).

As a result of the spread of the Argentine ant invasion, there is an ongoing process of biotic homogenization (Olden and Rooney 2006). Native ant communities become more similar across land uses following invasion. This is indicated by the clustering of invaded areas in contrast to uninvaded areas (Fig. 2), which were aligned along a habitat gradient. Moreover, the occupancy and abundance of native ants declined across most land uses after invasion, although the abundance-occupancy relationship in cork oak forests did not. This result contrasts with the above analysis of the annual rate of spread of the Argentine ant, which indicates no significant differences in the spread of the invasion among land uses. The maintenance of the occupancyabundance relationship in cork oak forests after the invasion can be explained by a higher impact of
L. humile in this land-use type, which led to the disappearance of some native ants that were thus excluded in the abundance-occupancy relationship of the invaded area.

\section{Conclusions}

Obtaining information on the assemblage of native ant communities before and after the invasion, together with the characteristics of the invaded sites, enabled us to gain unique insights into the relative roles of abiotic and biotic factors in determining the spread of the Argentine ant across various land-use types, and the linkages between factors influencing both the invasiveness and invasibility of natural ecosystems. Overall, results indicate that the spread of the Argentine ant into natural habitats is determined by proximity to urban areas and biotic characteristics of the invaded sites, and it is responsible for altering species assemblages and occupancy. On the other hand, when considering the role of habitat-related variables in particular, it becomes evident that variables determining the spread of the invasion differ to those variables that are greatly affected by the invasion.

Land uses per se contribute little to the spread of the invasion, but they indirectly influence the invasive success of $L$. humile by molding the microclimatic conditions of the site and the assemblage of native ant communities (Andersen 1995; Gómez et al. 2003). Conditions created by land uses may indirectly facilitate the spread of the Argentine ant, but also promote the development of well-established ant communities that pose a higher resistance to the invasion (Carpintero et al. 2007; Menke et al. 2007; Retana and Cerda 2000). This finding is extremely important when investigating the relative roles of biotic and abiotic factors in determining the distribution of invasive species across spatial scales (Willis and Whittaker 2002). Habitat-related variables might not have a direct influence on the spread, but they can indirectly affect both positively and negatively the establishment of the species. In this sense, a note of caution needs to be added when considering the relevance of habitat variables at local scales. Far from being a causal factor, habitat-related variables could simply be correlated with the result of opposite forces driving the pattern behind observation. To 
disentangle the influence of habitat variable in determining the distribution of species, it is critical to consider its multiple, interrelated effects on the variable of concern and divide the effects of habitat at the appropriate spatial scale (Olden and Rooney 2006).

Several studies have investigated the spread of L. humile at local scales, but few have conducted an analysis across various land-use types. Examining the spread of the invasion simultaneously in different environments has proved important to understand the relative role of biotic and abiotic factors driving patterns of biological diversity and composition, and the biotic homogenization process following species invasion (Retana and Cerda 2000). However, it remains to be tested whether these distribution patterns are exclusively regulated by biotic and abiotic factors (as shown herein), or can also by density-dependent processes conditioning the growth of Argentine ants once the population has reached a certain density (Haskins and Haskins 1988). Studies such as this are crucial for estimating the spread of invasive species, but also for predicting areas susceptible to invasion (i.e. the understanding of the invasiveness-invasibility relationship).

Acknowledgments Special thanks to A. Seglar and M. Rot for their unconditional assistance during the field work. C. Gómez, P. Pons, P.C. le Roux, J. Hortal, S. Clusella-Trullas, A. Terauds and two anonymous Referees provided valuable comments on the manuscript, X. Espadaler helped with the identification of ant species, and M. Clavero and M. De Cáceres provided valuable advice on statistical analysis. Financial support for this study came from Beatriu de Pinós Postdoctoral Grant (2006 BP-A 10124) from the Catalan Agency for Management of University and Research Grants (in support of NRP), the Ministry of Education and Science of the Spanish Government CGL200405240-C02-02/BOS (NRP and JMB).

\section{References}

Abril S, Oliveras J, Gomez C (2007) Foraging activity and dietary spectrum of the Argentine ant (Hymenoptera: Formicidae) in invaded natural areas of the northeast Iberian Peninsula. Environ Entomol 36:1166-1173

Alder P, Silverman J (2004) A comparison of monitoring methods used to detect changes in Argentine ant (Hymenoptera: Formicidae) populations. J Agric Urban Entomol 21:142-149

Andersen AN (1995) A classification of Australian ant communities, based on functional-groups which parallel plant life-forms in relation to stress and disturbance. J Biogeogr 22:15-29

Andren H (1994) Effects of habitat fragementation on birds and mammals in landscape with different proportions of suitable habitat-a review. Oikos 71:355-366

Blackburn TM, Cassey P, Gaston KJ (2006) Variations on a theme: sources of heterogeneity in the form of the interspecific relationship between abundance and distribution. J Anim Ecol 75:1426-1439

Bolger DT (2007) Spatial and temporal variation in the Argentine ant edge effect: Implications for the mechanism of edge limitation. Biol Conserv 136:295-305

Brown WL (2000) Diversity of ants. In: Agosti D, Majer JD, Alonso LE, Schultz TR (eds) Ants. Standard methods for measuring and monitoring biodiversity. Smithsonian Institution Press, Washington, DC, pp 45-79

Burnham KP, Anderson DR (2004) Multimodel inferenceunderstanding AIC and BIC in model selection. Sociol Method Res 33:261-304

Cammell ME, Way MJ, Paiva MR (1996) Diversity and structure of ant communities associated with oak, pine, eucalyptus and arable habitat in Portugal. Insectes Soc 43:37-46

Carpintero S, Reyes-Lopez J (2008) The role of competitive dominance in the invasive ability of the Argentine ant (Linepithema humile). Biol Invasions 10:25-35

Carpintero S, Reyes-Lopez J, de Reyna LA (2004) Impact of human dwellings on the distribution of the exotic Argentine ant: a case study in the Doñana National Park, Spain. Biol Conserv 115:279-289

Carpintero S, Retana J, Cerda X, Reyes-Lopez J, De Reyna LA (2007) Exploitative strategies of the invasive Argentine ant (Linepithema humile) and native ant species in a southern Spanish pine forest. Environ Entomol 36:11001111

Casellas D, Gómez C, Clavero M (2009) Comparing methods of evaluating the spread of Argentine ants in natural habitats: pitfall traps vs. baiting. Sociobiology 53:927938

Cerda X, Retana J, Cros S (1997) Thermal disruption of transitive hierarchies in Mediterranean ant communities. J Anim Ecol 66:363-374

de Kock AE, Giliomee JH (1989) A survey of the Argentine ant Iridomyrmex humilis Mayr Hymenoptera Formicidae in South African Fynbos. J Entomol Soc S Afr 52:157164

Espadaler X, Gómez C (2003) The Argentine ant, Linepithema humile, in the Iberian Peninsula. Sociobiology 42:187192

Gaston KJ, Blackburn T (2000) Pattern and process in macroecology. Blackwell, Oxford

Gómez C, Casellas D, Oliveras J, Bas JM (2003) Structure of ground-foraging ant assemblages in relation to land-use change in the northwestern Mediterranean region. Biodivers Conserv 12:2135-2146

Gotelli NJ, McCabe DJ (2002) Species co-occurrence: a metaanalysis of J. M. Diamond's assembly rules model. Ecology 83:2091-2096

Hartley S, Lester PJ (2003) Temperature-dependent development of the Argentine ant, Linepithema humile (Mayr) (Hymenoptera: Formicidae): a degree-day model with 
implications for range limits in New Zealand. N Z Entomol 26:91-100

Haskins CP, Haskins EF (1988) Final observations on Pheidole megacephala and Iridomyrmex humilis in Bermuda. Psyche 95:177-184

Heller NE, Gordon DM (2006) Seasonal spatial dynamics and causes of nest movement in colonies of the invasive Argentine ant (Linepithema humile). Ecol Entomol 31:499-510

Heller NE, Sanders NJ, Shors JW, Gordon DM (2008) Rainfall facilitates the spread, and time alters the impact, of the invasive Argentine ant. Oecologia 155:385-395

Holway DA (1998) Factors governing rate of invasion: a natural experiment using Argentine ants. Oecologia 115: 206-212

Holway DA (1999) Competitive mechanisms underlying the displacement of native ants by the invasive Argentine ant. Ecology 80:238-251

Hui C, McGeoch MA (2008) Does the self-similar species distribution model lead to unrealistic predictions? Ecology 89:2946-2952

Human KG, Gordon DM (1996) Exploitation and interference competition between the invasive Argentine ant, Linepithema humile, and native ant species. Oecologia 105:405412

Human KG, Weiss S, Weiss A, Sandler B, Gordon DM (1998) Effects of abiotic factors on the distribution and activity of the invasive Argentine ant (Hymenoptera: Formicidae). Environ Entomol 27:822-833

Hurlbert SH (1990) Spatial-distribution of the montane unicorn. Oikos 58:257-271

Johnson CN (1998) Species extinction and the relationship between distribution and abundance. Nature 394:272-274

Jumbam KR, Jackson S, Treblanche JS, McGeoch MA, Chown SL (2008) Acclimation effects on critical and lethal thermal limits of workers of the Argentine ant, Linepithema humile. J Insect Physiol 54:1008-1014

Koleff P, Gaston KJ, Lennon JJ (2003) Measuring beta diversity for presence-absence data. J Anim Ecol 72:367382

Krushelnycky PD, Joe SM, Medeiros AC, Daehler CC, Loope LL (2005) The role of abiotic conditions in shaping the long-term patterns of a high-elevation Argentine ant invasion. Divers Distrib 11:319-331

Lennon JJ, Koleff P, Greenwood JJD, Gaston KJ (2001) The geographical structure of British bird distributions: diversity, spatial turnover and scale. J Anim Ecol 70:966979

Lindsey JK (2000) Applying generalized linear models. Springer, Berlin

Lockwood JL, Cassey P, Blackburn T (2005) The role of propagule pressure in explaining species invasions. Trends Ecol Evol 20:223-228

Mack RN, Lonsdale WM (2001) Humans as global plant dispersers: getting more than we bargained for. Bioscience 51:95-102

Magurran AE (1988) Ecological diversity and its measurement. Princeton University Press, Princeton

Menke SB, Fisher RN, Jetz W, Holway DA (2007) Biotic and abiotic controls of argentine ant invasion success at local and landscape scales. Ecology 88:3164-3173
Ninyerola M, Pons X, Roure JM (2000) A methodological approach of climatological modelling of air temperature and precipitation through GIS techniques. Int $\mathrm{J}$ Climatol 20:1823-1841

Olden JD, Rooney TP (2006) On defining and quantifying biotic homogenization. Global Ecol Biogeogr 15:113-120

Passera L (1994) Characteristics of tramp species. In: Williams DF (ed) Exotic ants. Biology, impact, and control of introduced species. Westview Press, Boulder, pp 23-43

Pauchard A, Shea K (2006) Integrating the study of non-native plant invasions across spatial scales. Biol Invasions 8:399-413

Pinheiro J, Bates D, DebRoy S, Sarkar D, the R Core team (2008) nlme: linear and nonlinear mixed effects models. R package version 3.1-90

Quinn GP, Keough MJ (2002) Experimental design and data analysis for biologists. Cambridge University Press, Cambridge

R Development Core Team (2008) R: a language and environment for statistical computing. R Foundation for Statistical Computing, Vienna

Retana J, Cerda X (2000) Patterns of diversity and composition of Mediterranean ground ant communities tracking spatial and temporal variability in the thermal environment. Oecologia 123:436-444

Richardson DM, Pysek P (2006) Plant invasions: merging the concepts of species invasiveness and community invasibility. Prog Phys Geog 30:409-431

Richardson DM, Pysek P, Rejmánek M, Barbour MG, Panetta FD, West CJ (2000) Naturalization and invasion of alien plants: concepts and definitions. Divers Distrib 6:93-107

Roura-Pascual N, Bas JM, Thuiller W, Hui C, Krug RM, Brotons L (2009) From introduction to equilibrium: reconstructing the invasive pathways of the Argentine ant in a Mediterranean region. Glob Change Biol 15:21012115

Sagata K, Lester PJ (2009) Behavioural plasticity associated with propagule size, resources, and the invasion success of the Argentine ant Linepithema humile. J Appl Ecol 46:1927. doi:10.1111/j.1365-2664.2008.01523.x

Schiffman SS, Reynolds ML, Young FW (1981) Introduction to multidimensional scaling: theory, methods, and applications. Academic Press, New York

Schilman PE, Lighton JRB, Holway DA (2007) Water balance in the Argentine ant (Linepithema humile) compared with five common native ant species from southern California. Physiol Entomol 32:1-7

SMC (2006) Meteorological Service of Catalonia (http:// www.meteocat.com). Generalitat de Catalunya, Servei Meteorològic de Catalunya, Barcelona

Suarez AV, Bolger DT, Case TJ (1998) Effects of fragmentation and invasion on native ant communities in coastal Southern California. Ecology 79:2041-2056

Suarez AV, Holway DA, Case TJ (2001) Patterns of spread in biological invasions dominated by long-distance jump dispersal: insights from Argentine ants. P Natl Acad Sci USA 98:1095-1100

Ward PS (1987) Distribution of the introduced Argentine ant (Iridomyrmex-humilis) in natural habitats of the Lower Sacramento Valley and its effects on the indigenous ant fauna. Hilgardia 55:1-16 
Way MJ, Cammell ME, Paiva MR, Collingwood CA (1997) Distribution and dynamics of the Argentine ant Linepithema (Iridomyrmex) humile (Mayr) in relation to vegetation, soil conditions, topography and native competitor ants in Portugal. Insectes Soc 44:415-433

Willis KJ, Whittaker RJ (2002) Ecology—species diversityscale matters. Science 295:1245-1248
Wilson RJ, Thomas CD, Fox R, Roy DB, Kunin WE (2004) Spatial patterns in species distributions reveal biodiversity change. Nature 432:393-396

Wilson JR, Dormontt EE, Prentis PJ, Lowe AJ, Richardson DM (2009) Something in the way you move: dispersal pathways affect invasion success. Trends Ecol Evol 24:136-144 